\title{
An Evaluation of the Operation of the Railway E-Ticketing System
}

\section{Lili Fan, Xinhua Liu, Jianwen Wang}

Economics and Management College, Southwest Jiaotong University, Chengdu, China.

Email: fanlili1106@126.com

Received March $7^{\text {th }}, 2012$; revised March $19^{\text {th }}, 2012$; accepted April $8^{\text {th }}, 2012$

\begin{abstract}
In this paper, the operation smooth of the railway computer ticket system was evaluated. First, we design the evaluation index system, determine the subjective weights of the various technical indicators of the ticketing system with Fuzzy evaluation method, determine the index weight with the Entropy method, and analyze important factors affecting the system operation according to the health evaluation results of the ticketing system over the years.
\end{abstract}

Keywords: Computer Ticketing System; Evaluation; Technical Indicators

\section{Introduction}

Railway "whole railway ticket sale and reservation system" is a nationwide computer network covering railway ticketing system. It is an advanced modern ticketing system using computer to generate the ticket seats, sale, reservation, ticketing and a series of statistics and settlement services [1,2].

With the popularity of the railway e-ticketing system, ticket outlets are increasingly large and more efficient. In the event of failure, it not only affects the ticket but also difficult to maintain them. This requires an e-ticketing system has a high running stability and reliability, while the stability and reliability of system running rest on in a variety of technical factors of decision-supporting systems. Therefore, in order to make e-ticketing system running well, you should evaluate the condition over the years, understand their technical condition, monitor the key factors affecting system operation to timely correct. The following takes a railway station computer ticketing system as an example to do empirical research on the above ideas $[3,4]$.

A city railway station began in 1997 to use electronic ticketing system, running status fluctuated in the last 13 years and the accidents which affect the ticket occurred, which proves that the system running stability and reliability has problems. This article evaluates its 6 years using condition to analyze the reasons. Firstly we design the main technical index system which effect the ticketing system, then determine the ticketing system of each technical index of subjective weights using fuzzy evaluation method, and use the entropy method [5] to determine the synthetical weight of each index, at last analysis important factors affecting system operation according to the evaluation results of ticketing system over the operation status.

\section{Technical Index System}

In this paper, the following aspects of the ticketing system are used to establish the evaluation index system [6] of running effect:

1) Reliability: The system failed for two reasons: the first is hardware failure and the second is the software error. The operator cannot handle a hardware failure and it has to be repaired by the maintenance department. The main manifestation of software errors is computer operating system instability or crashes caused by running computer, which can all be almost resolved by restarting the terminals. Therefore reliability is used to measure the hardware failure rate (ratio of times of hardware failure per month and the number of terminals) [7].

2) Stability: Software error rate (ratio of times of software error per month and the number of terminals) is used to measure the stability.

3) Energy conservation: To measure it by the ratio of the power consumption of the entire system and the number of ticket sales (KWH/per million contracts).

4) Running efficiency: We calculate the number of each hour of ticket machine as the running efficiency of the system according to total number of tickets of the year, and hours of ticket vending machines at all terminals of the system.

5) Running ability: It is measured by the year's total 
number of ticket sale.

6) Runing security: It is measured by the ratio of security of the database and the total times of equipment failures and terminal number of system [8].

7) Running veracity: The operating system instability or dislocation of printing device may make ticketing terminals vend invalid tickets, we measure the veracity by the invalid ticket ratio that year.

8) Availability: Calculating the ratio of rated system working time and actual time to measure the system's availability.

\section{The City Railway Station Computer Ticketing System Data Base}

1) The ticket selling terminal number and ticket number is shown in Table $\mathbf{1 .}$

2) The average monthly number of hardware failures and software errors, the amount of energy consumption, the system invalidated the rate each year, the number of accidental damage to equipment damage and the average number of databases, the downtime of failures is shown in Table 2.
3) Mean down time of various faults is shown in Table 3 .

The 2004 to 2010 each technical evaluation index values is summarized in Table 4.

Table 3 value normalized [9] is shown in Table 5 .

Each index of state, Reliability: A hardware failure rate which is the nonlinear inverse index; Operation stability: Nonlinear inverse index; Energy saving: Power consumption and terminal is directly proportional to the number, and inversely to the ticket number, which is linear inverse index; Efficiency: A positive linear index; Operation: Linear positive index; Running accuracy: nonlinear

Table 1. The ticket selling terminal number and a year's ticket number.

\begin{tabular}{cccccccc}
\hline & 2004 & 2005 & 2006 & 2007 & 2008 & 2009 & 2010 \\
\hline Station terminal number & 18 & 18 & 22 & 25 & 25 & 25 & 25 \\
City terminal number & 7 & 11 & 12 & 12 & 12 & 13 & 15 \\
Ticket number (millions) & 498 & 502 & 525 & 499 & 580 & 620 & 556 \\
\hline
\end{tabular}

Terminal station work 20 hours a day, working eight hours a day the city terminal.

Table 2. Raw data.

\begin{tabular}{|c|c|c|c|c|c|c|c|}
\hline & 2004 & 2005 & 2006 & 2007 & 2008 & 2009 & 2010 \\
\hline Hardware fault rate & 3 & 5 & 2 & 6 & 2 & 3 & 3 \\
\hline Software error rate & 8 & 11 & 9 & 7 & 4 & 6 & 5 \\
\hline Electricity consumption (KWH ) & 134320 & 141328 & 160600 & 173740 & 173740 & 175492 & 178996 \\
\hline Number of invalid ballots (Zhang) & 36500 & 40600 & 57324 & 40552 & 45954 & 41040 & 51600 \\
\hline Total ticket sales (millions) & 498 & 502 & 525 & 499 & 580 & 620 & 556 \\
\hline Invalidations rate (\%) & 0.73 & 0.81 & 1.09 & 0.81 & 0.79 & 0.66 & 0.93 \\
\hline Equipment accident damage number & 2 & 2 & 4 & 6 & 1 & 2 & 1 \\
\hline Database, the number of damaged & 0 & 0 & 0 & 0 & 0 & 0 & 0 \\
\hline
\end{tabular}

Table 3. Faults mean down time.

\begin{tabular}{lcccc}
\hline & Hardware fault & Software error & Equipment accident damage & Database damage \\
\hline Down time (hours) & 1.25 & 0.5 & 1.25 \\
\hline
\end{tabular}

Table 4. The technical evaluation index value induced.

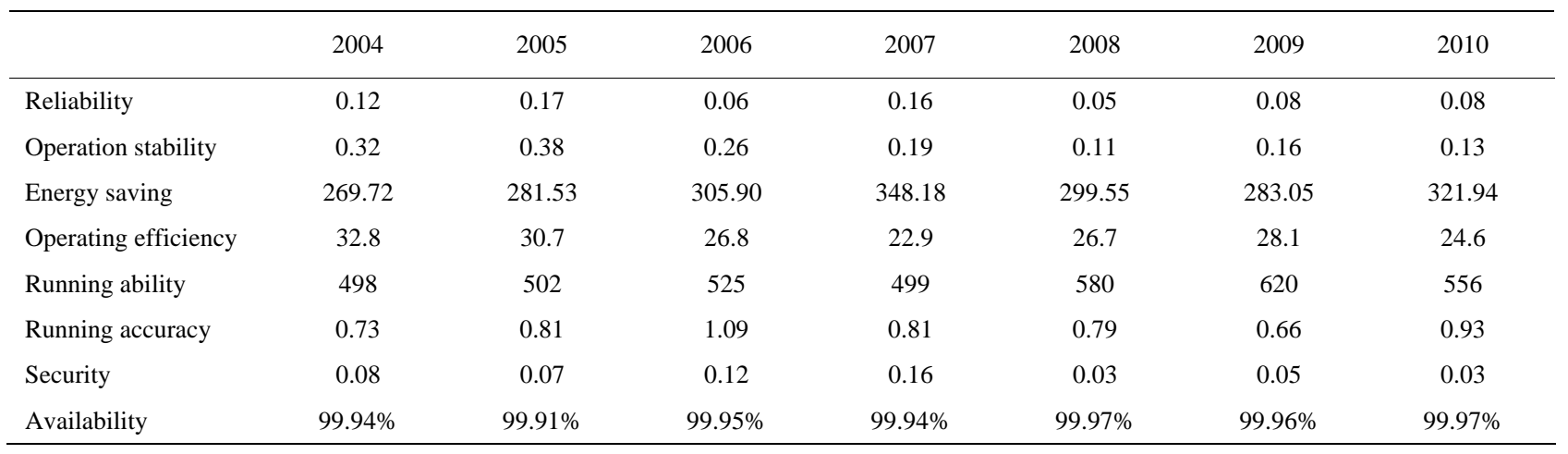


inverse index. Safety: nonlinear inverse index. Availability: linear positive index.

\section{Determine Indexes' Weight}

Because of the long service life of equipment, the staffs understand the specific use of the device state, the equipment of the technical indicators and the actual work related degree. Therefore, through interviews with them, it is feasible to use fuzzy comprehensive evaluation method to determine the weight of each index, which is close to the actual work. The important indicators of rank score is shown in Table 6.

Using fuzzy comprehensive evaluation method [10] to determine the levels of index weight, the results is shown in Tables 7-9.

Table 5. Standardization of evaluation index value.

\begin{tabular}{lccccccc}
\hline & 2004 & 2005 & 2006 & 2007 & 2008 & 2009 & 2010 \\
\hline Reliability & 25.41 & 16.78 & 41.80 & 18.24 & 45.42 & 35.40 & 35.40 \\
Operation stability & 20.22 & 15.96 & 25.62 & 33.76 & 49.29 & 38.01 & 42.78 \\
Energy saving & 69 & 62 & 47 & 21 & 51 & 61 & 37 \\
Efficiency & 76 & 66 & 46 & 27 & 46 & 53 & 36 \\
Running ability & 35 & 37 & 45 & 36 & 64 & 78 & 56 \\
Running accuracy & 39.94 & 31.77 & 14.25 & 31.77 & 33.64 & 48.82 & 22.53 \\
Security & 30 & 32.60 & 21.52 & 15.45 & 45.42 & 38.48 & 45.42 \\
Availability & 45 & 18 & 54 & 45 & 73 & 64 & 73 \\
\hline
\end{tabular}

In order to meet the requirements of the entropy method, we need to eliminate index hierarchy, and converse it to index weight. The results are in Table $\mathbf{1 0 .}$

\section{Calculate Entropy Weight and Synthetical Weights of Various Indexes}

Use the Excel tool for calculating the comprehensive

Table 6. Indicators of important rating score.

\begin{tabular}{lccc}
\hline $\begin{array}{c}\text { Qualitative } \\
\text { evaluation }\end{array}$ & $\begin{array}{c}\text { Index } \\
\text { value }\end{array}$ & $\begin{array}{c}\text { Qualitative } \\
\text { evaluation }\end{array}$ & $\begin{array}{c}\text { Index } \\
\text { value }\end{array}$ \\
\hline Absolutely minor & 10 & Slightly important & 60 \\
Strong minor & 20 & Obviously important & 70 \\
Obviously minor & 30 & Strongly important & 80 \\
Slightly minor & 40 & Absolutely important & 90 \\
The same & 50 & & \\
\hline
\end{tabular}

Table 7. Technology and quality indicators.

\begin{tabular}{lccc}
\hline & Reliability & Stability & Energy saving \\
\hline Clear minor (30) & & & 3 \\
Minor (40) & & & 5 \\
General (50) & & & 2 \\
Strongly important (80) & 2 & 6 & \\
Absolutely important (90) & 8 & 4 & \\
Total score & 880 & 840 & 390 \\
Simplify & 0.42 & 0.40 & 0.18 \\
\hline
\end{tabular}

Table 8. Operation improvement indexes.

\begin{tabular}{|c|c|c|c|c|c|}
\hline & Efficiency & Running ability & Security & Running accuracy & Availability \\
\hline Clear minor (30) & & & 3 & & \\
\hline Minor (40) & & & 5 & & \\
\hline General (50) & & 3 & 2 & & \\
\hline Slightly important (60) & 4 & 2 & & 2 & \\
\hline Obviously important (70) & 3 & 1 & & 2 & \\
\hline Strongly important (80) & 2 & 4 & & 6 & 2 \\
\hline Absolutely important (90) & 1 & & & & 8 \\
\hline Total score & 700 & 660 & 390 & 740 & 880 \\
\hline Simplify & 0.21 & 0.20 & 0.12 & 0.22 & 0.26 \\
\hline
\end{tabular}

Table 9. Technology quality and operation improvement indexes.

\begin{tabular}{lcc}
\hline & Technology quality index & Operation improvement index \\
\hline Slightly important (60) & 4 & \\
Obviously important (70) & 3 & 2 \\
Strongly important (80) & 3 & 8 \\
Absolutely important (90) & & 880 \\
Total score & 690 & 0.56 \\
Simplify & 0.44 & \\
\hline
\end{tabular}


Table 10. Eliminate index hierarchy and converse it to index weight.

\begin{tabular}{cccc}
\hline Index & Subjective weight value & Index & Subjective weight value \\
\hline Reliability & 0.18 & Running ability & 0.11 \\
Stability & 0.18 & Running security & 0.07 \\
Energy saving & 0.08 & Running accuracy & 0.12 \\
Efficiency & 0.12 & Availability & 0.15 \\
\hline
\end{tabular}

Table 11. Comprehensive weights.

\begin{tabular}{cccc}
\hline Index & Synthetical weight value & Index & Synthetical weight value \\
\hline Reliability & 0.19 & Running ability & 0.09 \\
Stability & 0.19 & Security & 0.07 \\
Energy saving & 0.07 & Running accuracy & 0.12 \\
Efficiency & 0.10 & Availability & 0.16 \\
\hline
\end{tabular}

Table 12. The comprehensive index value and the evaluation results.

\begin{tabular}{lccccccc}
\hline & 2004 & 2005 & 2006 & 2007 & 2008 & 2009 & 2010 \\
\hline Synthetical weights value & 38.52 & 30.07 & 37.54 & 28.89 & 52.08 & 49.50 & 45.40 \\
Sort by best small to large & 4 & 6 & 5 & 7 & 1 & 3 & 2 \\
\hline
\end{tabular}

weights shown in Table 11.

Based on the above data over the comprehensive index value and the evaluation results, the calculation results are shown in Table 12.

\section{Analysis and Conclusions}

Score of 2007 is the lowest, which is due to the equipment fault rate is relatively high and stability is poor. In 2008 the comprehensive score is the highest, which is due to the equipment operation is stable, while the volume is higher. The above data reflects stable and normal equipment operation is very important. In future work we must strengthen equipment maintenance and repair operation, reduce failure rate, improve equipment stability.

This article analysis important factors affecting system operation according to the evaluation results of ticketing system over the operation status and the conclusion helps people effective recognize stability is the basis for railway station to enhance the system running stability and reliability. Ability to accurately assess the system running stability and reliability enables stations to perfectly understand their running status thus target for improvement.

\section{REFERENCES}

[1] L. Z. Wang, "Railway E-Ticketing System Introduction," Modern Communication, No. 9, 2006, pp. 11-12.
[2] S. L. Chan, "Information Technology in Business Processes,” Business Process Management Journal, Vol. 6, No. 3, 2000, pp. 224-237.

[3] D. Haneberg, "Electronic Ticketing: Risks in E-Commerce Applications,” Digital Excellence, 2008, pp. 55-66.

[4] A. Sulaiman, J. Ng, et al., "E-Ticketing as a New Way of Buying Tickets: Malaysian Perceptions,” Journal of Social Science, Vol. 17, No. 2, 2008, pp. 149-157.

[5] Y. W. Qiu, "Management Decision and Applied Entropy Theory,” Mechanical Industry Press, Beijing, 2002.

[6] B. K. Zheng, "Equipment, Technical and Economic Evaluation and Its Application,” China Equipment Management, No. 4, 2000, pp. 7-8.

[7] J. Soszynska, "Reliability Evaluation of a Port Oil Transportation System in Variable Operation Conditions," International Journal of Pressure Vessels and Piping, Vol. 83, No. 4, 2006, pp. 304-311.

[8] J. Taylor, A. Maitra, et al., "Evaluation of the Impact of Plug-in Electric Vehicle Loading on Distribution System Operations," Power \& Energy Society General Meeting, 26-30 July 2009, pp. 1-6.

[9] K. L. Zhu, "Evaluation of Non-Linear Non-Dimensional Fuzzy Approach,” Statistics and Information Forum, No. 3, 1997, pp. 10-14.

[10] W. Q. Zhang, Y. Zhang and L. Q. Jiang, "Entropy-Based Decision Evaluation Model and Its Application,” Journal of Systems Engineering, Vol. 10, No. 3, 1995, pp. 69-74. 